\title{
The usage of Recycled Glass In Hot Mix Asphalt: A Review
}

\author{
A. O. A. Baqadeem 1 , F. M. Jakarni2, A. K. S. Al-Shakhrit1 and K. A. Masri1,3* \\ ${ }^{1}$ College of Engineering, Universiti Malaysia Pahang, Lebuhraya Tun Razak, 26300, Gambang, Kuantan, Pahang, Malaysia \\ ${ }^{2}$ Faculty of Engineering, Universiti Putra Malaysia, 43400 Serdang, Selangor. \\ 3Earth Resources and Sustainability Centre (ERAS), Universiti Malaysia Pahang, 26300 Gambang, Pahang, Malaysia
}

\begin{abstract}
Waste material has been defined as any type of material by-product of human or industrial activity that has no residual value. The elimination of waste glass in landfills become a serious challenging task which several countries look out on it on all sides of the world. Reusing of glass waste for road construction is a sustainable solution to environmental and ecological problems. Reusing of glass waste will reduce the construction cost of pavement, reduce the landfill cost. This study has done to review the overall performance of asphalt concrete blend, in which several exceptional combinations of aggregate is replaced with various proportions of crashed glass. This review is discussed some main properties of asphalt mixture, such as stability and flow. The results shown that the stability was higher than that of the glass waste samples and decreasing as the glass waste increasing. In general, the research displays that using glass waste in asphalt mixture is acceptable.
\end{abstract}

ARTICLE HISTORY

Received: $29^{\text {th }}$ Mar 2021

Revised: $30^{\text {th }}$ Apr 2021

Accepted: 28th May 2021

KEYWORDS

Waste Material

Glass Waste

Asphalt Mixture

Stability

\section{INTRODUCTION}

Nowadays, using a lot of granite in construction and granite is not sustainable and cannot be grown, so one day granite will be difficult to find it. According to the U.S. Geological Survey, domestic production of granite in the U.S. was estimated to be 1.48 billion tons in 2016 and according to the latest trading data from ITC, India exported total 1.65 million tones in volume of granite [1]. One day, we will not have these nature materials for construction.

As a result of industrialization and urbanization it has been estimated that several million tons of waste glasses are generated annually worldwide. The prime sources of waste glasses are waste containers, window screen, window glasses, tube lights, bulbs, electronic equipment, medicinal bottles and liquor bottles. Due to the high cost of cleaning and color sorting, only a small proportion can be recycled by specific market like container manufacturers. In many countries, the recycling of waste glass is especially significant as its recycling rate is quite low, compared to other solid wastes [18].

Although glass is a non-metallic material that cannot be broken or burned, and many countries have recently included glass in their specifications, there is still no use of recycled glass. More growing glass waste in landfills and landfills worldwide represents a loss of economic and environmental costs [19].

There are many applications that can use recycled glass, such as using glass as aggregate in road base and sub-base, mixing it with aspalt, mixing it with pipe slabs, mixing and ornaments for building construction, filters, accessories and bed linen, mixes and materials. That one. In addition, recycling and recycling of waste can reduce the need for natural resources, which can eventually lead to environmental degradation..

\section{REVIEW}

\section{Materials Used as Filler in Asphalt Mixture}

\section{Limestone}

Chasanah et al [2] has studied the feasibility of the use of limestone as filler in AC-WC mixture and to identify the effects of limestone addition on the Marshall Characteristics, Durability, Indirect Tensile Strength (ITS), and Permeability. The first stage was to test the properties of materials consisting of aggregate, asphalt, and limestone. The second stage was to determine the optimum asphalt content with $0 \%, 25 \%, 50 \%, 75 \%$, and 100\% filler proportions, and the last stage was to conduct the Marshall, Immersion, ITS, and Permeability tests. The results showed that limestone has been in accordance with the performance requirements specified for a filler of AC-WC mixture using Starbit E-55 asphalt as a binder. There was a change in the Marshall characteristics of optimum asphalt content. The durability increased, and the ITS values of AC-WC mixture improved along with the increase in limestone proportion. However, the permeability test indicated that the mixture has a poor drainage feature towards water after variation in filler proportions was performed.

\section{Cement dust}

According to [1], the effect of using waste cement dust as a mineral filler on the mechanical properties of hot mix asphalt was investigated. The optimum cement dust content was determined. The studied mechanical properties include 
Marshall properties, indirect tensile strength, and unconfined compressive strength. Five asphalt concrete mixtures with various cement dust contents, namely; $0 \%, 25 \%, 50 \%, 75 \%$ and $100 \%$ by weight of the limestone mineral filler were studied. Laboratory testing has revealed an enhancement in Marshall and mechanical properties of asphalt concrete mixtures when cement dust was used. Marshall testing results have indicated an increase in the stability, unit weight and a decrease in the flow, voids ratio and voids in mineral aggregates when the percentage of cement dust content increases. The indirect tensile strength and unconfined compressive strength have also increased as the ratio of cement dust increased. The optimum cement dust ratio was found to be $100 \%$ of the used mineral filler. Hence, cement dust can totally replace limestone mineral filler in asphalt paving mixtures.

\section{Fly ash}

This study investigates the effect of using fly ash (FA) in asphalt mixture as replace- mend of common filler. In view of the same, samples were prepared for different bitumen as varying percentage of FA ranging from 2 to $8 \%$ as alternative filler in modified mixes. The content $(3.5-6.5 \%$ at $0.5 \%$ increments) by using $2 \%$ hydrated lime (HL) in control mix as well optimum bitumen content (OBC) was then determined for all the mix by Marshall mix design. Experimental results indicated higher stability value with lower OBC for the mixture having 4\% FA as optimum filler content in comparison with conventional mix and standard specification. So this study discuss the feasibility of using FA as alternative filler instead of HL in asphalt concrete mix by satisfying the standard specification [3].

\section{Rice husk ash}

[4] accordingly, in this laboratory study, it was investigated to use Rice Husk Ash (RHA) instead of conventional mineral filler in hot asphalt mixtures. The mechanical properties were assessed by conducting Marshall Stability and Indirect Tensile Strength tests. While moisture damage and long-term aging were inspected by determining Index of Retained Strength (IRS) and Mean Marshall Stability Ratio (MMSR), respectively. The experimental results have shown a significant improvement in the mechanical properties and a substantial upgrading in durability of the produced mixtures i.e. asphalt concrete mixtures with RHA as a mineral filler (RHAAC) in comparison with the control mixtures which were prepared with OPC as a mineral filler (OPCAC). As a result of this study, RHA can be incorporated instead of conventional mineral filler in asphalt concrete mixtures particularly in areas where there is extensive RHA waste

\section{Ceramic dust}

It has been expected that about $30 \%$ of the annual production in the ceramic industry is converted to waste during cutting, grinding, dressing and polishing operations. This waste ceramic could be easily crushed to the desired size and form ceramic dust which could be utilized as filler. Most ceramic materials such as fire ware scrap are made from Kaolin clay, which has low moisture sensitivity due to its water-insoluble nature and have no harmful decomposition products. Improvement in Marshall Stability and rutting resistance at higher OBC were observed when CW was introduced in asphalt concrete and SMA as compared to conventional fillers. This was due to high strength, porous nature and higher absorption of bitumen on surface of CW. SMA Mixes prepared with CW filler having particle size in between 0.075 and $0.020 \mathrm{~mm}$ had better cohesive strength than that pre- pared with limestone filler in the same size range. This resulted in enhanced resistance to fatigue cracking and moisture-induced damage [5].

\section{Waste concrete dust and brick dust}

[6] studied the effect of types of filler on the behavior of bituminous mixes. According the properties of bituminous mixes containing filler like waste concrete dust and brick dust is studied and compared with the mixes containing filler like fine sand and stone dust mixture generally used. The Marshall method of mix design was used for the comparison. The Marshall stabilities of mix types containing filler fine sand and stone dust mixture, waste concrete dust and brick dust were found $9.8 \mathrm{KN}, 11.1 \mathrm{KN}$ and $11.3 \mathrm{KN}$ respectively which satisfy the limiting value of $5.33 \mathrm{KN}$ according to Marshall Design criteria. The study indicates the possibility of using waste concrete dust and brick dust as filler in bituminous mix.

\section{Marble dust}

According to [7] the purpose of this research is to study the use of Marble dust as a filler in asphalt concrete In Bituminous Wearing Course, in addition to reduce the harmful waste materials. Asphalt mixtures was done by using marble dust at $(5,6,7,8) \%$ by weight of total aggregate using the Marshall method. The changes in the properties of the asphalt mixtures are investigated, then compared with the asphalt mixtures designed using the traditional filler (Limestone Powder, Portland Cement) at the same rates as before. The main outcome of this research is the possibility of using Marble Dust as filler in asphalt mixtures at optimum Marble dust content is $6 \%$, which obtained the highest stability and values of flow and air voids are good and within the limits of the international standards ASTM.

\section{Coal Waste Ash}

[8] assessed the performance of mastics and SMA mixture containing coal waste ash (CWA) and rice husk ash (RHA) in different mass fractions $(0 \%, 25 \%, 50 \%, 75 \%$ and $100 \%)$ as a substitution of limestone powder (LP) as conventional filler. For this purpose, the Multiple Stress Creep Recovery (MSCR) and linear Amplitude Sweep (LAS) tests were performed to investigate the rutting and fatigue performance of asphalt mastics with different fillers and concentrations. Moreover, Marshall Stability, resilient modulus, dynamic creep, moisture susceptibility, wheel track, indirect tensile strength tests were implemented to investigate the mechanical performance of mixtures. The MSCR test results revealed 
that addition of RHA to original binder led to decrease in strain of binder and hence rutting strength of original binder increases at both stress levels. While the CWA additive has adverse effect in comparison with RHA. Based on the obtained results from LAS test, addition of RHA to original binder increases the fatigue life of binder. Adversely, CWA is incapable of improving the fatigue behavior of mas- tics. Also, modification of mastics with SBS improves the fatigue behavior of modified asphalt binders. Results indicated that replacement of RHA by conventional filler enhances the Marshall stability, resilient modulus, rutting properties, moisture resistance and tensile strength of asphalt mixtures. Adversely, the modification of asphalt binder by CWA is resulting in reducing the mentioned performance properties of mixtures, except moisture resistance. In general, the obtained results from this study indicated that reuse of RHA and CWA waste materials in north part of Iran where there are lots of RHA and CWA materials especially RHA in pavement engineering, has two main effects. First, reduce environmental problems. Second, enhance the performance properties of mixtures.

\section{Effects of Waste Glass Powder as a Mineral Fillers on Properties of Asphalt-Concrete Mixture}

Filler is one of the components of asphalt concrete mixture. It plays a significant role on the characteristics and performance of the asphalt concrete mixtures [9]. The filler could increase the resistance of particle to move within the mix matrix and/or works as an active material when it interacts with the asphalt cement to change the properties of the mastic. Fillers have traditionally been used in asphalt mixtures to fill the voids between the larger aggregate particles. The influence of different types of fillers on the properties of asphalt concrete mixture varies with the particle size, shape, surface area, surface texture and other physio-chemical properties.

The micro structural investigations showed that cracks were reduced using mineral fillers which may be due to the even distributions of particles [10]. Rheological studies of modified binders with fly ash Class F revealed best performance against rutting as compared to stone dust and brick dust. [11] used the crushed glass from bottles in HMA instead of fine aggregate and filler in binder coarse. The author conducted his experimental works by replacing the glass by $2.5-15 \%$ from both the weight of filler and fine aggregate. The results indicated that $7.5 \%$ was the optimum value for all asphalt mix characteristics.

\section{Crushed Glass as A Fine Aggregate In Asphalt Mixture}

In 2013, it was estimated that more than 92.53 million tons of asphalt concrete were produced around the globe. The largest two producers of bituminous concrete are the U.S.A. and China, with 17.57 and 16.27 million tons produced respectively [12]. Table tabulates the asphalt concrete production of the top producers globally.

Table 1: Top producers of asphalt concrete as listed by [12]

\begin{tabular}{|l|l|}
\hline Country & $\begin{array}{l}\text { Total production asphalt } \\
\text { concrete in 2013 (million } \\
\text { tonnes) }\end{array}$ \\
\hline United States of America & 17.57 \\
China & 16.27 \\
Russian Federation & 5.61 \\
India & 4.34 \\
Canada & 3.93 \\
Iran & 3.53 \\
Japan & 3.32 \\
Republic of Korea & 3.28 \\
Germany & 3.09 \\
Italy and San Marino & 2.82 \\
Turkey & 2.65 \\
Brazil & 2.41 \\
Saudi Arabia & 2.22 \\
Singapore & 2.02 \\
Spain & 1.90 \\
France (including Monaco) & 1.75 \\
\hline
\end{tabular}

\section{Effects of Waste Glass as a Fine Aggregate on Properties of Asphalt-Concrete Mixture Stability and Flow Test}

Several studies $[13,14]$ showed that the stability declined with the increase of glass replacement. But it can be improved by introducing hydrated lime or liquid antistripping agent.

Ogundipe et al. [17] studied the performance of pavement asphalt in which a fractional fine aggregate is replaced with windscreen crushed glass. The original sample is prepared without adding glass for three different percentages of bitumen $(4.5,5,5.5 \%)$. Other samples are prepared by adding crushed glass to the mix with $5 \%, 10 \%$, and $15 \%$ by aggregate weight. The results of stability and flow for asphalt-glass mix with conventional mix showed that there is an improvement at $10 \%$ glass especially at low bitumen percentage (less than 5\%). Also, it was found that bulk specific gravity (Gmb) decreases with the increase of glass percentage in the mix. Air voids in the samples decreases with the increase of bitumen 
percentage. The average values of Marshall Test parameters with different glass percentage were summarized in Table 2 below.

Table 2: Average Marshall test results (Issa 2016)

\begin{tabular}{|c|c|c|c|c|}
\hline Type & $\begin{array}{c}0 \% \\
\text { Glass }\end{array}$ & $\begin{array}{c}5 \% \\
\text { Glass }\end{array}$ & $\begin{array}{c}10 \% \\
\text { Glass }\end{array}$ & $\begin{array}{c}15 \% \\
\text { Glass }\end{array}$ \\
\hline $\begin{array}{c}\text { Stability } \\
(\mathrm{KN})\end{array}$ & 13.4 & 12.66 & 13.92 & 13.07 \\
\hline Flow (mm) & 2.93 & 2.8 & 2.87 & 2.73 \\
\hline Gmb & 2.4 & 2.25 & 2.13 & 2.1 \\
\hline Air voids & 4.74 & 4.53 & 4.3 & 4.16 \\
\hline
\end{tabular}

Al-Khateeb et al. [15] used three specimens at each asphalt content (AC) (4, 5, 6 and 7\%) were tested for stability, flow, air voids (AV), voids in mineral aggregate (VMA) and voids filled with bitumen (VFA). The optimum asphalt content (OAC), which was the average of asphalt contents that meet optimum stability, maximum unit weight and $4 \%$ air voids, was determined as follows.

By using different percentages of glass waste of $5 \%, 10 \%, 15 \%$ and $20 \%$, the optimum binder content was found to be $5.75 \%$ for $0 \%, 5.615 \%$ for $5 \%, 5.35 \%$ for $10 \%, 5.65 \%$ for $15 \%$ and $5.68 \%$ for $20 \%$ of glasphalt, as indicated in Table 1 to

Table 5.

Table 1: 0\% glass content of asphalt

\begin{tabular}{|c|c|c|c|c|c|c|c|}
\hline \multicolumn{7}{|c|}{$0 \%$ Glass } \\
\cline { 1 - 6 } AC & OAC & Density & Stability & AV & VMA & VFA & $\begin{array}{c}\text { FLOW } \\
\text { in }\end{array}$ \\
\hline$\%$ & $\%$ & $\mathrm{~g} / \mathrm{cm}^{3}$ & $\mathrm{~kg}$ & $\%$ & $\%$ & $\%$ & 13.04 \\
\hline 4 & 3.85 & 2.174 & 8492 & 8.36 & 16.68 & 50.02 & 15.60 \\
\hline 5 & 4.76 & 2.2019 & 9999 & 6.04 & 16.45 & 63.09 & 16.86 \\
\hline 6 & 5.67 & 2.214 & 10439 & 4.31 & 16.72 & 73.80 & 19.26 \\
\hline 7 & 6.54 & 2.2025 & 10229 & 3.58 & 17.91 & 80.01 & \\
\hline
\end{tabular}

AV: Air Voids, VMA: Voids in Mineral Aggregate \& VFA: Voids Filled with Bitumen.

Table 2: 5\% glass content of asphalt

\begin{tabular}{|c|c|c|c|c|c|c|c|}
\hline \multicolumn{7}{|c|}{$5 \%$ Glass } \\
\cline { 1 - 6 } AC & OAC & Density & Stability & AV & VMA & VFA & $\begin{array}{c}\text { FLOW } \\
\text { in }\end{array}$ \\
\hline$\%$ & $\%$ & $\mathrm{~g} / \mathrm{cm}^{3}$ & $\mathrm{~kg}$ & $\%$ & $\%$ & $\%$ & 14.50 \\
\hline 4 & 3.85 & 2.123 & 10641 & 10.28 & 18.39 & 44.10 & 16.45 \\
\hline 5 & 4.76 & 2.172 & 11008 & 7.67 & 17.87 & 57.11 & 17.50 \\
\hline 6 & 5.67 & 2.251 & 12949 & 2.74 & 15.36 & 82.18 & 18 \\
\hline 7 & 6.54 & 2.237 & 9707 & 2.13 & 16.63 & 87.21 & 26.00 \\
\hline
\end{tabular}

Table 3: 10\% glass content of asphalt

\begin{tabular}{|c|c|c|c|c|c|c|c|}
\hline \multicolumn{70}{|c|}{$10 \%$ Glass } \\
\cline { 1 - 6 } AC & OAC & Density & Stability & AV & VMA & VFA & \multirow{2}{*|}{$\begin{array}{c}\text { FLOW } \\
\text { in }\end{array}$} \\
\hline$\%$ & $\%$ & $\mathrm{~g} / \mathrm{cm}^{3}$ & $\mathrm{~kg}$ & $\%$ & $\%$ & $\%$ & 12.99 \\
\hline 4 & 3.85 & 2.137 & 10471 & 10.32 & 18.45 & 44.22 & 15.00 \\
\hline 5 & 4.76 & 2.174 & 11696 & 7.58 & 17.83 & 57.51 & 17.00 \\
\hline 6 & 5.67 & 2.247 & 9627 & 3.30 & 15.89 & 79.28 & 19.10 \\
\hline 7 & 6.54 & 2.241 & 8153 & 2.37 & 16.89 & 85.96 & 10 \\
\hline
\end{tabular}


Table 4: $15 \%$ glass content of asphalt

\begin{tabular}{|c|c|c|c|c|c|c|c|}
\hline \multicolumn{9}{|c|}{$15 \%$ Glass } \\
\hline AC & OAC & Density & Stability & AV & VMA & VFA & $\begin{array}{c}\text { FLOW } \\
\text { in }\end{array}$ \\
\hline$\%$ & $\%$ & $\mathrm{~g} / \mathrm{cm}^{3}$ & $\mathrm{~kg}$ & $\%$ & $\%$ & $\%$ & 16.06 \\
\hline 4 & 3.85 & 2.133 & 5813 & 10.18 & 18.30 & 44.38 & 16.46 \\
\hline 5 & 4.76 & 2.203 & 9498 & 6.04 & 16.42 & 63.27 & 18.82 \\
\hline 6 & 5.67 & 2.241 & 10992 & 3.54 & 16.05 & 77.97 & 22.85 \\
\hline 7 & 6.54 & 2.234 & 8901 & 2.01 & 16.53 & 87.83 & 22 \\
\hline
\end{tabular}

Table 5: 20\% glass content of asphalt

\begin{tabular}{|c|c|c|c|c|c|c|c|}
\hline \multicolumn{9}{|c|}{$20 \%$ Glass } \\
\hline AC & OAC & Density & Stability & AV & VMA & VFA & $\begin{array}{c}\text { FLOW } \\
\text { in }\end{array}$ \\
\hline$\%$ & $\%$ & $\mathrm{~g} / \mathrm{cm}^{3}$ & $\mathrm{~kg}$ & $\%$ & $\%$ & $\%$ & 11.48 \\
\hline 4 & 3.85 & 2.119 & 8103 & 10.75 & 18.82 & 42.93 & 14.78 \\
\hline 5 & 4.76 & 2.178 & 9701 & 7.26 & 17.51 & 58.71 & 16.28 \\
\hline 6 & 5.67 & 2.246 & 11349 & 2.65 & 15.29 & 83.31 & 17.79 \\
\hline 7 & 6.54 & 2.244 & 9080 & 2.37 & 16.84 & 85.98 & 17 \\
\hline
\end{tabular}

\section{Fatigue And Rutting Tests}

Fatigue and rutting are very well known to be the two popular distresses that occur in road pavement. These are mainly due to the increase in the number of vehicles particularly those with high axle loads, due to the environmental conditions and due to construction and design errors [16].

\section{Fatigue}

The reason of a fatigue test is to decide the life expectancy which will be anticipated from a material subjected to cyclic loading, however fatigue strength and crack resistance are commonly sought values as well. A fatigue test is also utilized for the determination of the maximum load that a sample can withstand for a specified number of cycles. Data from fatigue testing often are displaying in an S-N chart which is a plot of the number of cycles required to cause failure in a specimen against the amplitude of the cyclical stress developed.

\section{RESULT AND DISCUSSION}

The results of stability and flow for asphalt-glass mix with conventional mix showed that there is an improvement at $10 \%$ glass especially at low bitumen percentage [15]. There is potential to substitute depleting natural aggregates with crushed glass in asphalt mixes. This is based on the finding that asphalt mixes with crushed glass could outperform a conventional dense graded mix in terms of rutting and has comparable fatigue resistance at low strains.

As previously mentioned, the glass-asphalt mix contains $3 \%$ hydrated lime which acts as an anti-stripping agent. The anti-stripping characteristics of hydrated lime result in stronger cohesion between the aggregates and glass particles with the bitumen. Furthermore, the higher angularity of the glass particles, in comparison with the conventional aggregates, plays an important role in the increased dynamic modulus behavior of the glass-asphalt mix. It is suspected that the higher internal friction, which is due to the increased angularity of the glass particles, in turn increases the interlock between the particles which contributes to the increased dynamic modulus of the glass-asphalt mix [15].

From a technical perspective, asphalt with well crushed glass (e.g. $\leq 4.75 \mathrm{~mm}$ ) replacing a few percent (e.g. $10-15 \%)$ of fine aggregates should not be excluded from use in asphalt surface layers, as glass particles are ground too finely to present any safety risks, and polished stone value (PSV) and aggregate abrasion value (AAV) requirements apply only to coarse aggregates in the mixtures. However, this may pose a non-technical barrier as fine aggregates are only used in moderate amount in (SMA) and (OGFC), where recycled solid waste material (SWM) that can be used in larger size (e.g. steel slag) makes a better choice because of less processing requirements and a higher replacement rate. It is recognized that the replacement rate should be allowed to vary to the size of glass particles, and vice versa [18, 19].

According to [17], the results of the stability of the asphalt concrete with and without waste glass show the stability of asphalt concrete with waste glass increases as the glass content increases up till $18 \%$ and decreases with addition of $20 \%$ glass waste. Generally, the results show that the stability of the asphalt concrete incorporating waste glass is lower than the conventional asphalt concrete. The decrease in stability was caused by the fact that the waste glass was added as percentage of the total mix. The flow of the asphalt concrete with and without the waste glass show that the flow of 
asphalt concrete with waste glass reduces to $8 \%$, while it increases with the increasing glass content from 10 to $20 \%$. The high flow values recorded for the samples with the waste glass content of $16 \%, 18 \%$ and $20 \%$ indicate plastic mix.

\section{CONCLUSION AND RECOMMENDATION}

It can be concluded that, the data presented in this study show that there is a promising potential for the use of waste glass in asphalt concrete. It provides higher resilience modulus, but further investigations may be considered regarding its stability and high-performance properties. It contributes to recirculation of glass wastes as well as to the protection of the environment and will also lead to an ecofriendly sustainable construction method

\section{Recommendation}

To further the research, the following topics are recommended:

* Use more than one sieve size of aggregate to be replaced by glass waste and different percentages.

* Use small sizes of glass than used as larger gravel-sized glass particles are used, raveling and stripping may cause some problems such as deficient friction and lock resistance.

* Anti-stripping additives can be added to the mixtures to improve their moisture resistance and improve the adhesion. Hydrated lime is one of the most common and most effective of such additives.

\section{ACKNOWLEDGEMENT}

The authors would like to thank UMP for funding this work under an internal grant PDU203206.

\section{REFERENCES}

[1] Ahmed, Hassan Y., Ayman M. Othman, and Afaf A. Mahmoud. 2006. "EFFECT OF USING WASTE CEMENT DUST AS A MINERAL FILLER ON THE MECHANICAL PROPERTIES OF HOT MIX ASPHALT ABSTRACT : INTRODUCTION : MATERIAL CHARACTERIZATION : 1-Asphalt Binder :" 9(1):51-60.

[2] Chasanah, Faizul and Fajariesta Arta Putra. 2019. "Effects of Using Limestone as a Filler and Starbit E-55 Asphalt as a Binder on the Performance of AC-WC Mixture." MATEC Web of Conferences 258:04005.

[3] Mistry, Raja and Tapas Kumar. 2016. "Effect of Using Fly Ash as Alternative Filler in Hot Mix Asphalt \&." Perspectives in Science 8:307-9.

[4] Al-Hdabi, Abbas. 2016. "Laboratory Investigation on the Properties of Asphalt Concrete Mixture with Rice Husk Ash as Filler." Construction and Building Materials 126:544-51.

[5] Choudhary, Jayvant, Brind Kumar, and Ankit Gupta. 2020. "Utilization of Solid Waste Materials as Alternative Fillers in Asphalt Mixes: A Review." Construction and Building Materials 234:117271.

[6] Kathem Taeh Alnealy, Dipu Sutradhar. 2015. "Effect of Using Waste Material as Filler in Bituminous Mix Design.” American Journal of Civil Engineering 3(3):88.

[7] Fadel, Imad. 2019. "Using Marble Dust As A Filler In Asphalt Mixtures." (October 2017).

[8] Ameli, Alireza, Rezvan Babagoli, Navid Norouzi, Farhang Jalali, and Farzin Poorheydari Mamaghani. 2020. "Laboratory Evaluation of the Effect of Coal Waste Ash (CWA) and Rice Husk Ash (RHA) on Performance of Asphalt Mastics and Stone Matrix Asphalt (SMA) Mixture." Construction and Building Materials 236:117557.

[9] Ravindra Tomar, R. K. Jain and M. K. Kostha. 2013. "Effect of Fillers On Bituminous Paving Mixes." International Journal of Engineering and Research and Science \& Technology 2(January):5-7.

[10] Naveed, Haris, Zia ur Rehman, Ammad Hassan Khan, Sabih Qamar, and Majid Niaz Akhtar. 2019. "Effect of Mineral Fillers on the Performance, Rheological and Dynamic Viscosity Measurements of Asphalt Mastic." Construction and Building Materials 222:390-99.

[11] Dalloul, Khalil Nabil. 2013. "Submitted by: Khalil Nabil Dalloul Supervised by: Prof. Eng. Shafik Jendia."

[12] Mohajerani, Abbas, John Vajna, Tsz Ho Homan Cheung, Halenur Kurmus, Arul Arulrajah, and Suksun Horpibulsuk. 2017. "Practical Recycling Applications of Crushed Waste Glass in Construction Materials: A Review." Construction and Building Materials 156:443-67.

[13] Zakaria, Nur Mustakiza, Mohammad Kamal Hassan, Ahmad Nazrul Hakimi Ibrahim, Sri Atmaja P. Rosyidi, Nur Izzi Md Yusoff, Abdullahi Ali Mohamed, and Norhidayah Hassan. 2018. "The Use of Mixed Waste Recycled Plastic and Glass as an Aggregate Replacement in Asphalt Mixtures.” Jurnal Teknologi 80(1):79-88.

[14] Anochie-Boateng, J. K. and T. B. George. 2017. "Exploring Waste Glass in Hot-Mix Asphalt." Roads \& Bridges (April):3134.

[15] Al-Khateeb, Ghazi G., Motaz F. Irfaeya, and Taisir S. Khedaywi. 2017. “A New Simplified Micromechanical Model for Asphalt Mastic Behavior." Construction and Building Materials 149(November):587-98.

[16] Moghaddam, Taher Baghaee, Mohamed Rehan Karim, and Mahrez Abdelaziz. 2011. "A Review on Fatigue and Rutting Performance of Asphalt Mixes." Scientific Research and Essays 6(4):670-82.

[17] Ogundipe, Olumide Moses and Emeka Segun Nnochiri. 2020. "Evaluation of the Effects of Waste Glass in Asphalt Concrete Using the Marshall Test.” Engineering Review 40(2):24-33.

[18] Issa, Y. 2016. "Effect of Adding Crushed Glass to Asphalt Mix." Archives of Civil Engineering 62(2):35-44.

[19] Huang, Yue, Roger N. Bird, and Oliver Heidrich. 2007. "A Review of the Use of Recycled Solid Waste Materials in Asphalt Pavements." 52:58-73. 